\title{
Study on Critical Stages and Critical Sterility Point of Thermo-Sensitive Genic Male Sterile Lines of Rice for Two Line Hybrid Production
}

\author{
K. Sai Rekha ${ }^{1}$, M. Kumar ${ }^{2}$, R. Saraswathi, S. Mannonmani ${ }^{3}$ and M. Raveendran ${ }^{4}$ \\ ${ }^{1}$ Department of Rice, ${ }^{2}$ Department of Cotton, ${ }^{3}$ Department of Oilseeds, \\ ${ }^{4}$ Centre for Plant Molecular Breeding and Biotechnology, \\ Tamil Nadu Agricultural University, Coimbatore-003, India \\ *Corresponding author
}

A B S T R A C T

K e y w o r d s
TGMS,
Critical Sterility
Point,
Two line hybrid,
Critical stage,
Critical sterility
temperature

The genic male sterile rice (GMS) sensitive to temperature during the panicle development period is a novel type of germplasm in rice, which is sterile under high temperature condition but fertile in low temperature condition. A number of TGMS lines have been popularly used in commercial seed production of hybrid rice in China and India. To fix the duration of critical sterility temperature expression of TGMS lines for hybrid seed production, eight TGMS lines developed by Department of Rice, Tamil Nadu Agricultural University were sown in weekly intervals from December 16, 2015 to January 27, 2016. Heading date and pollen sterility were observed on each line during every planting interval. The data showed that the critical stage for most of the TGMS lines occurred during panicle development stages and approximately 26 to 5 days before heading. The pollen sterility recorded on the plants raised at weekly interval revealed that all lines had stable sterile phase with $100 \%$ pollen sterility for more than 40 consecutive days during high temperature conditions. TGMS lines TNAU45S, TNAU60S, TNAU95S, GDR 61S and GDR 70S were identified to have critical sterility point (CSP) at a mean temperature of above $29^{\circ} \mathrm{C}$. The TGMS lines viz., TNAU45S, TNAU60S, TNAU 95S and GDR61S were performing stable even during mild changes in temperature and these lines are considered as stable lines and can be recommended for hybrid seed production. Evaluating TGMS lines using this new strategy was found to be more stable in terms of sterility expression and these lines can efficiently used for Two line hybrid production.

\section{Introduction}

Rice is the most important cereal of Asia and is an overwhelming staple food in most population of this region. It is grown in more than 100 countries and there are around 18,000 varieties accounting for about $25 \%$ of the World's food grain production. The green revolution in many rice producing countries enabled global rice production to meet the demands of the World's increasing population. However, by 2025, the World must increase rice production to 880 million tonnes from the present 560 million tonnes (FAO). Recent progress in breeding techniques enables the possibility of increasing yield through hybrid rice production.

Currently, CMS system is the most widely used male sterility system for hybrid rice production. Although effective, three-line 
system of hybrid rice breeding is expensive and cumbersome. Meanwhile, in three line system of hybrid rice breeding maintaining restorer lines for fertility restoration of A line is a major limiting factor. The two line system of hybrid breeding utilizing environment sensitive genic male sterility (EGMS) is better choice to overcome problems associated with three line breeding and can increase the rice global production globally. Tropical countries like India where more temperature coincides with most of the days and where day length differences are marginal, temperature sensitive genic male sterility (TGMS) system is considered more useful than the photoperiod sensitive genic male sterility (PGMS) system (Virmani, 1996). In order to exploit this novel male sterility in heterosis breeding, characterization of new TGMS lines and finding out critical stages for expression of sterility and fertility are very essential. In this context, the present study was taken up to fix the duration of critical sterility temperature expression of selected TGMS lines for hybrid seed production.

\section{Materials and Methods}

Eight TGMS lines developed at Tamil Nadu Agricultural University (TNAU), Coimbatore and Hybrid Rice Evaluation Centre, Gudalur through pedigree breeding programme were taken for evaluation. The lines used in this experiment are TNAU39S, TNAU45S, TNAU60S, TNAU95S, GDR 29S, GDR 61S, GDR 10S and GDR 70S. These lines were sown in weekly interval from Dec 16, 2015 to Jan 27, 2016 for seven weeks. These lines were planted in single row, with 12 plants per row in spacing of $30 \times 20 \mathrm{~cm}$. Days to first flowering for each genotype was recorded. At the heading stage, 5-6 spikelets from primary panicles from two plants in each line were collected (Sanchez \& Virmani, 2005). The anthers were crushed and stained with $1 \%$ Iodine- potassium iodide (I-KI) solution. Pollen sterility was observed under microscope and was scored using scale reported by Virmani et al., (1997). These lines were characterized for their sterility behaviour and critical stages for two line hybrid production.

\section{Identifying sterile phase}

From the seven sets of data on pollen sterility, the sterile phase of each TGMS line and the duration of each phase were identified. The flowering period, in which the lines were completely sterile ( $100 \%$ pollen sterility), was taken as sterile phase. The period in which the plants recorded more than 50 per cent pollen fertility was considered as fertile phase. The period of partial sterility was considered as the phase of fertility transition (Latha and Thiyagarajan, 2010).

\section{Relative influence of temperature on sterility}

Data available on maximum temperature, minimum temperature and mean temperature from 1-30 days before heading available at Paddy Breeding Station, Tamil Nadu Agricultural University (TNAU), Coimbatore were used. This period corresponds to the panicle development of rice plant from differentiation of first bract primordia to complete formation of spikelets (Virmani \& Sharma 1993).

\section{Critical sterility temperature}

The Critical Sterility Temperature (CST) is the temperature at which the line becomes sterile from fertile condition. The lowest mean temperature among the temperatures inducing sterility was considered as the critical sterility temperature.

\section{Results and Discussion}

The multiplication of TGMS lines and seed production of two- line hybrids is not a difficult task as that of 3- line hybrids which 
require the additional maintenance of a maintainer line to multiply sterile line. The TGMS lines are sensitive to temperature are even mild fluctuations in temperature leads to fertility. However, sterile, fertile and fertility transition phases of TGMS lines need to be determined so that hybrid seed production on a larger scale could be possible. The sterility behaviour of TGMS lines at different dates of sowing is depicted in Fig 1 to 8.

Among the eight lines, TNAU45S, TNAU60S, TNAU95S and GDR61S exhibited $100 \%$ sterility in all seven dates of sowing. The GDR 70S line showed partial sterility at first date of sowing and TNAU39S showed partial sterility at first and second dates of sowing. The GDR 29S showed 100\% sterility at last two dates of sowing in January and the other line GDR 10S showed $100 \%$ sterility in last four dates of sowing.
Comparing the data among seven staggered sowings, it is noticed that all lines showed $100 \%$ sterility in last two dates of sowing (21.01.2016 \& 27.01.2016). So, these dates of sowing are recommended for all TGMS lines for hybrid seed production.

Considering this fact that there is a certain amount of risk in exploiting rice heterosis by means of TGMS if temperature fluctuation occurs at critical stages of panicle development (Wu, 1997), therefore, idea on critical stage for alteration in sterility behaviour is useful to determine the most suitable time of sowing the TGMS lines for hybrid seed production. The appropriate sowing dates of TGMS lines should be determined in such a way that a critical stage of panicle development would be exposed to the required temperature (Latha and Thiyagarajan, 2010).

Table.1 Days to first flowering, critical stages and critical sterility points of eight TGMS lines

\begin{tabular}{|c|c|c|c|c|c|c|}
\hline Lines & Date of sowing & \multirow{2}{*}{$\begin{array}{c}\text { Days to } \\
\text { first }\end{array}$} & \multirow{2}{*}{$\begin{array}{c}\text { Critical } \\
\text { Stage }\end{array}$} & \multicolumn{2}{c|}{$\begin{array}{c}\text { Critical Sterility } \\
\text { Temperature }\end{array}$} & Sterility \% \\
\cline { 4 - 6 } & & flowering & & Range & Mean & \\
\hline 39S & 16.12 .2015 & 85 & $60-80$ & $26.1-29.9$ & 28.28 & 98 \\
\hline & 23.12 .2015 & 85 & $60-80$ & $26.8-31.1$ & 28.95 & 98 \\
\hline & 30.12 .2015 & 85 & $60-80$ & $27.3-31.55$ & 29.61 & 100 \\
\hline & 07.01 .2016 & 85 & $60-80$ & $27.5-31.55$ & 30.18 & 100 \\
\hline & 13.01 .2016 & 84 & $59-79$ & $28.3-31.5$ & 30.59 & 100 \\
\hline & 21.01 .2016 & 85 & $60-80$ & $28.3-32.35$ & 30.73 & 100 \\
\hline & 27.01 .2016 & 85 & $60-80$ & $28.3-32.6$ & 30.91 & 100 \\
\hline $\mathbf{4 5 S}$ & 16.12 .2015 & 105 & $80-100$ & $27.5-31.55$ & 29.97 & 100 \\
\hline & 23.12 .2015 & 105 & $80-100$ & $28.3-31.55$ & 30.59 & 100 \\
\hline & 30.12 .2015 & 105 & $80-100$ & $28.3-32.35$ & 30.68 & 100 \\
\hline & 07.01 .2016 & 106 & $81-101$ & $28.3-32.35$ & 30.91 & 100 \\
\hline & 13.01 .2016 & 104 & $79-99$ & $29.4-32.6$ & 31.26 & 100 \\
\hline & 21.01 .2016 & 104 & $79-99$ & $29.4-32.6$ & 31.57 & 100 \\
\hline & 27.01 .2016 & 103 & $78-98$ & $25.2-32.2$ & 29.97 & 100 \\
\hline $\mathbf{6 0 S}$ & 16.12 .2015 & 95 & $70-90$ & $27.3-31.1$ & 29.25 & 100 \\
\hline & 23.12 .2015 & 100 & $75-95$ & $27.5-31.55$ & 30.18 & 100 \\
\hline & 30.12 .2015 & 98 & $73-93$ & $28.3-31.55$ & 30.58 & 100 \\
\hline & 07.01 .2016 & 100 & $75-95$ & $28.3-32.35$ & 30.8 & 100 \\
\hline
\end{tabular}


Int.J.Curr.Microbiol.App.Sci (2017) 6(5): 2128-2135

\begin{tabular}{|c|c|c|c|c|c|c|}
\hline & 13.01 .2016 & 95 & $70-90$ & $28.3-32.6$ & 30.88 & 100 \\
\hline & 21.01 .2016 & 95 & $70-90$ & $29.4-32.6$ & 31.23 & 100 \\
\hline & 27.01 .2016 & 98 & 73-93 & $25.2-32.4$ & 30.48 & 100 \\
\hline \multirow[t]{7}{*}{$95 \mathrm{~S}$} & 16.12 .2015 & 110 & $85-105$ & $28.3-31.55$ & 30.48 & 100 \\
\hline & 23.12 .2015 & 110 & $85-105$ & $28.3-31.55$ & 30.64 & 100 \\
\hline & 30.12 .2015 & 108 & $83-103$ & $28.3-32.35$ & 30.88 & 100 \\
\hline & 07.01 .2016 & 110 & $85-105$ & $29.4-32.6$ & 31.31 & 100 \\
\hline & 13.01 .2016 & 106 & $81-101$ & $29.4-32.6$ & 31.36 & 100 \\
\hline & 21.01 .2016 & 106 & $81-101$ & $29.4-32.6$ & 31.53 & 100 \\
\hline & 27.01 .2016 & 109 & 84-104 & $29.4-32.6$ & 31.44 & 100 \\
\hline \multirow[t]{7}{*}{ GDR29S } & 16.12 .2015 & 99 & $74-94$ & $27.3-31.3$ & 29.49 & 50 \\
\hline & 23.12 .2015 & 100 & $75-95$ & $27.5-31.55$ & 30.18 & 95 \\
\hline & 30.12 .2015 & 98 & 73-93 & $28.3-31.55$ & 30.58 & 95 \\
\hline & 07.01 .2016 & 101 & $76-96$ & $28.3-32.6$ & 30.88 & 98 \\
\hline & 13.01 .2016 & 98 & $73-93$ & $28.3-32.6$ & 30.88 & 95 \\
\hline & 21.01 .2016 & 98 & $73-93$ & $29.4-32.6$ & 31.36 & 100 \\
\hline & 27.01 .2016 & 102 & $77-97$ & $25.2-32.2$ & 29.99 & 100 \\
\hline \multirow[t]{7}{*}{ GDR61S } & 16.12 .2015 & 95 & $70-90$ & $27.3-31.1$ & 29.25 & 100 \\
\hline & 23.12 .2015 & 99 & 74-94 & $27.5-31.55$ & 30.08 & 100 \\
\hline & 30.12 .2015 & 98 & $73-93$ & $28.3-31.55$ & 30.58 & 100 \\
\hline & 07.01 .2016 & 99 & 74-94 & $28.3-32.35$ & 30.73 & 100 \\
\hline & 13.01 .2016 & 98 & $73-93$ & $28.3-32.6$ & 30.88 & 100 \\
\hline & 21.01 .2016 & 98 & $73-93$ & $29.4-32.6$ & 31.36 & 100 \\
\hline & 27.01 .2016 & 97 & $72-92$ & $25.2-32.4$ & 30.67 & 100 \\
\hline \multirow[t]{7}{*}{ GDR10S } & 16.12 .2015 & 86 & $61-81$ & $26.1-29.1$ & 28.35 & 50 \\
\hline & 23.12 .2015 & 85 & $60-80$ & $26.8-31.1$ & 28.95 & 50 \\
\hline & 30.12 .2015 & 86 & $61-81$ & $27.3-31.55$ & 29.71 & 50 \\
\hline & 07.01 .2016 & 85 & $60-80$ & $27.5-31.55$ & 30.18 & 100 \\
\hline & 13.01 .2016 & 86 & $61-81$ & $28.3-31.55$ & 30.57 & 100 \\
\hline & 21.01 .2016 & 86 & $61-81$ & $28.3-32.35$ & 30.8 & 100 \\
\hline & 27.01 .2016 & 87 & $62-82$ & $29.4-32.6$ & 31.14 & 100 \\
\hline \multirow[t]{7}{*}{ GDR70S } & 16.12 .2015 & 105 & $80-100$ & $27.5-31.55$ & 29.97 & 98 \\
\hline & 23.12 .2015 & 104 & $79-99$ & $28.3-31.55$ & 30.54 & 100 \\
\hline & 30.12 .2015 & 106 & $81-101$ & $28.3-32.35$ & 30.74 & 100 \\
\hline & 07.01 .2016 & 105 & $80-100$ & $28.3-32.6$ & 30.88 & 100 \\
\hline & 13.01 .2016 & 105 & $80-100$ & 29.4-32.6 & 31.31 & 100 \\
\hline & 21.01 .2016 & 104 & $79-99$ & $29.4-32.6$ & 31.57 & 100 \\
\hline & 27.01 .2016 & 105 & $80-100$ & $29.4-32.6$ & 31.31 & 100 \\
\hline
\end{tabular}


Fig.1 Sterility behaviour of TNAU 39S

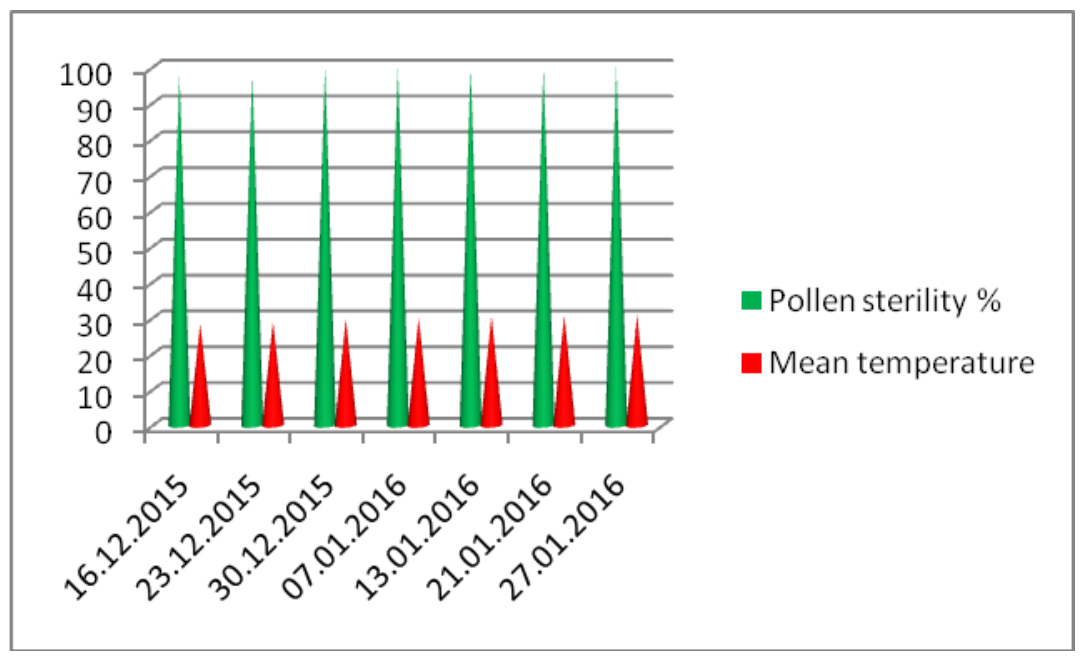

Fig.2 Sterility behaviour of TNAU 45S

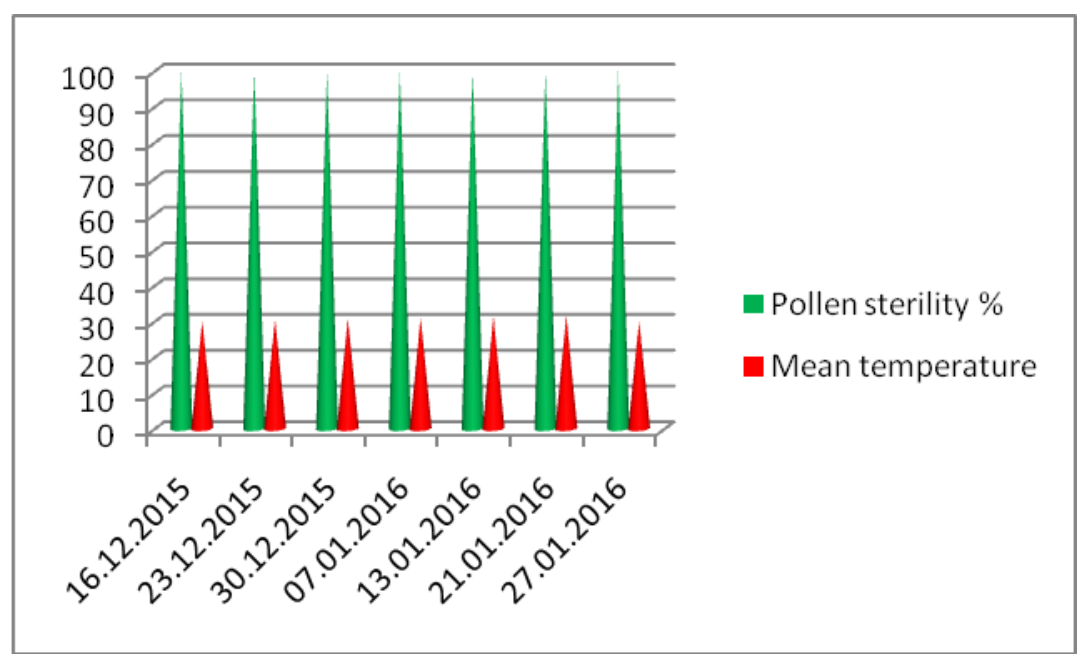

Fig.3 Sterility behaviour of TNAU 60S

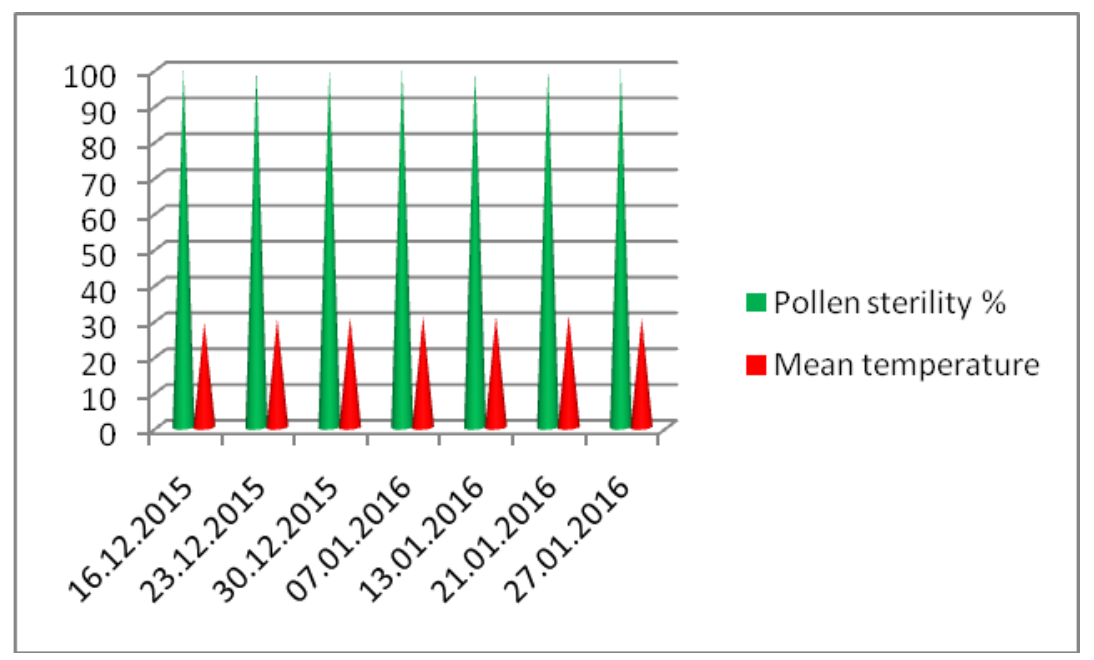

Fig.4 Sterility behaviour of TNAU 95S

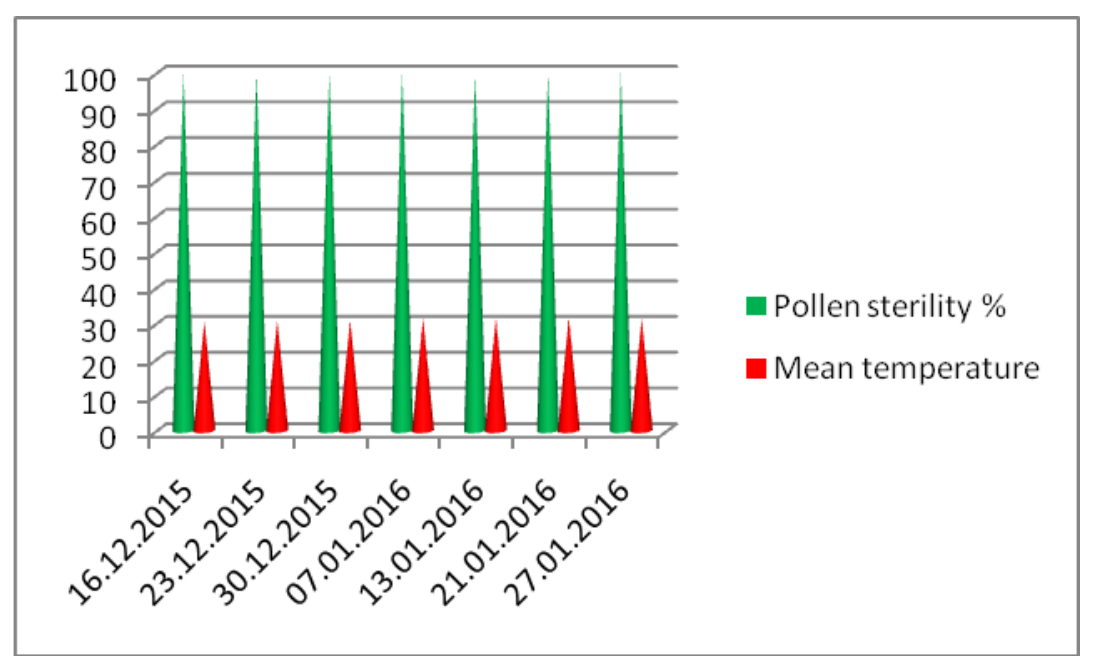


Fig.5 Sterility behaviour of GDR 29S

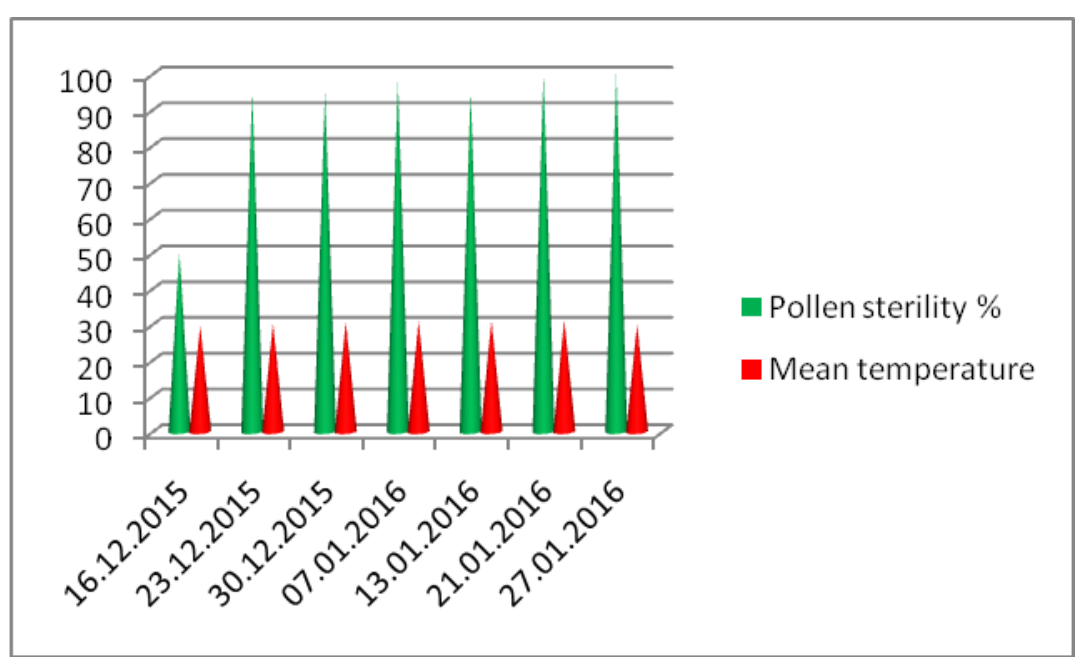

Fig.6 Sterility behaviour of GDR 61S

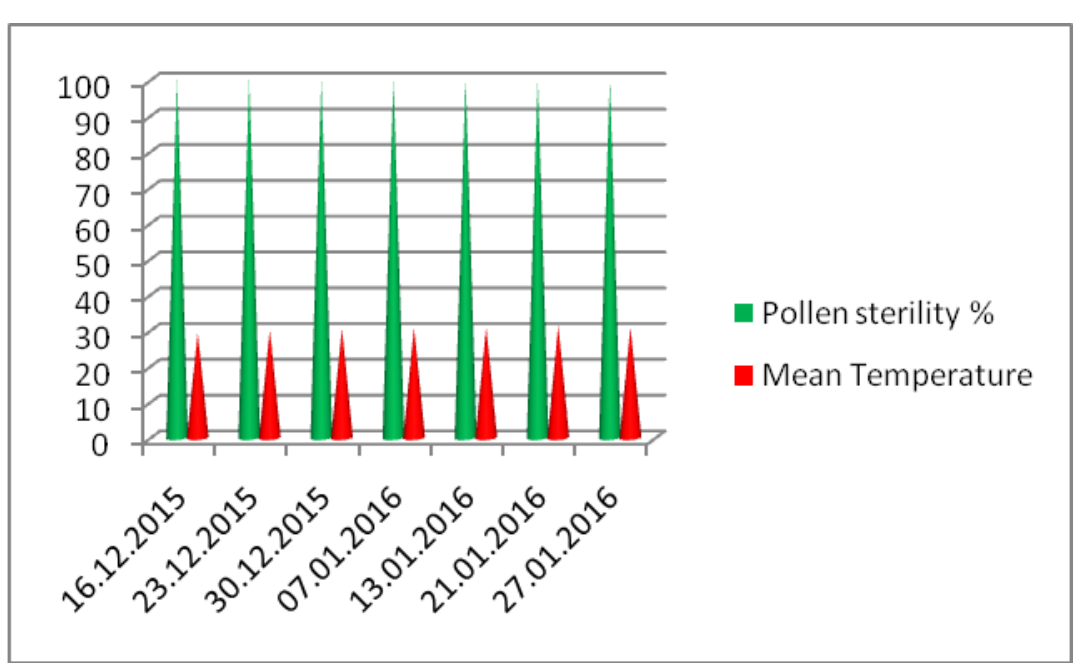

Fig.7 Sterility behaviour of GDR 10S

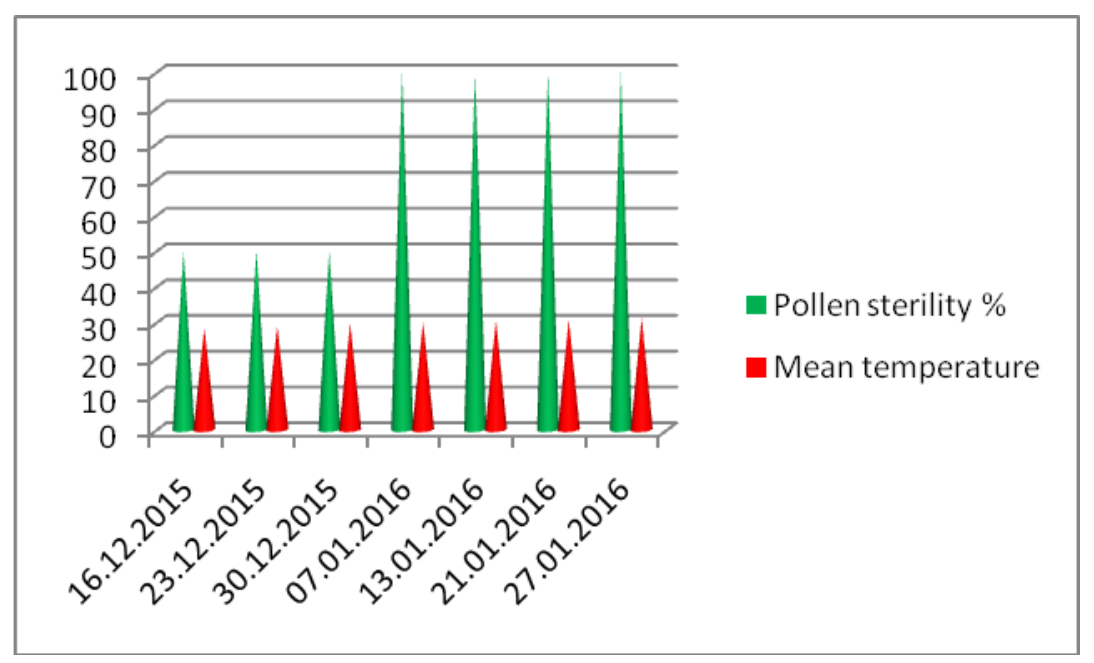

Fig.8 Sterility behaviour of GDR 70S

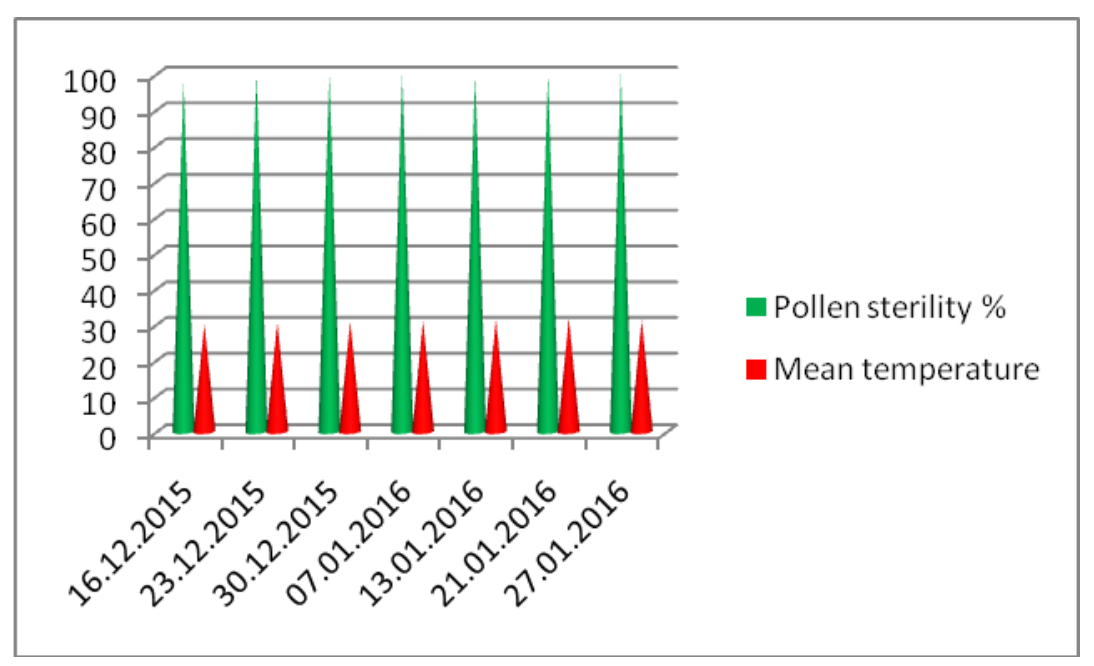


The stages of panicle development sensitive to mean temperature varied among the lines. Early stages of panicle development were sensitive to temperature in TNAU 39S $\left(28.28^{\circ} \mathrm{C}\right), \quad$ GDR29S $\left(29.49^{\circ} \mathrm{C}\right), \quad$ GDR $10 \mathrm{~S}$ $\left(28.35^{\circ} \mathrm{C}\right)$ and GDR70S $\left(29.97^{\circ} \mathrm{C}\right)$. Low temperature prevailing during early stages of panicles development before pre meiotic division causes sterility in these lines. The remaining TGMS lines viz., TNAU45S, TNAU60S, TNAU 95S and GDR61S were performing stable even in the mild changes in temperature. So, these lines are considered as stable lines and can be recommended for hybrid seed production. The panicle developmental stages from stamen and pistil primordial differentiation to meiotic division of pollen mother cell have been reported as critical stages for different TGMS lines in other studies (Borkakati and Virmani, 1997).

The eight lines studied had different days to first heading. Days to first heading is also an important factor since the early duration lines facing low temperature during panicle development stage will lead to sterility alteration. Among the eight lines, TNAU 39S and GDR29S are early in duration which is having of low temperature during flowering $\left(<29^{\circ} \mathrm{C}\right)$ and these lines were showing partial sterility during first few dates of sowing. The range of mean temperatures varied among the lines. The mean temperature ranging from 26.1-32. $6^{\circ} \mathrm{C}$ was recorded for lines TNAU39S and GDR 10S during panicle development stage over all the seven dates of sowing. Likewise, lines TNAU45S, TNAU60S, GDR29S and GDR61S had a range of mean temperature of $25.2^{\circ} \mathrm{C}-32.6^{\circ} \mathrm{C}$, GDR70S had $27.5^{\circ} \mathrm{C}-32.6^{\circ} \mathrm{C}$ and TNAU95S was having $28.3^{\circ} \mathrm{C}-32.6^{\circ} \mathrm{C}$.

The critical temperature inducing sterility must be relatively low i.e., $23^{\circ} \mathrm{C}$ in temperate zone and $24^{\circ} \mathrm{C}$ in subtropics (Yuan, 1998). The lines with more critical temperature $\left(>26^{\circ} \mathrm{C}\right)$ are not favorable for commercial exploitation since even a short fall in temperature during summer months may cause fertility reversion in TGMS lines which may lead to self seed set. The critical stages and CSP of the TGMS lines are summarized in Table 1. The critical temperature for sterility alteration of TNAU45S, TNAU60S and GDR61S was $25^{\circ} \mathrm{C}$ and it was $26^{\circ} \mathrm{C}$ for TNAU39S and GDR10S and $28^{\circ} \mathrm{C}$ for TNAU 95S and 27.5 for GDR70S. All these lines satisfy the need for commercial exploitation of 2- line hybrid production in rice. The changes in the CSP in these lines might be due to different genetic background and similar results was also been reported by Mou et al., (1998) and Viraktamath \& Virmani (2001).

The maximum and minimum temperature during the panicle developmental stages inducing sterility was around $36 / 20^{\circ} \mathrm{C}$ in most of the flowering months. Since all the lines were completely sterile for more than 40 consecutive days during sterile phase, hybrid seed production utilizing these lines can be taken up in Coimbatore by raising the lines in such a way that flowering coincides with the sterile phase. At Coimbatore, the lines TNAU 45S, TNAU 60S, TNAU 95S, GDR 61S and GDR 70S can be taken up sowing from December month and for TNAU39S, GDR29S and GDR 70S, sowing can be taken from January for hybrid seed production. Lu et al., (1998) suggested that for successful utilization of TGMS lines, the sterile and fertile phases should coexist at least for 30 consecutive days.

It is concluded that the results of this study showed that all TGMS lines have clearly defined sterile phases. The TGMS lines TNAU45S, TNAU60S, TNAU 95S, GDR61S and GDR70S are recommended for sowing from December to February while TNAU 39S, TNAU GDR29S and GDR10S lines must be sown by first week of January. The 
CST (Critical Sterility Temperature) for all these lines is identified in the range of $25.2^{\circ} \mathrm{C}$ $28.3^{\circ} \mathrm{C}$. Hence, all these lines can be exploited commercially for the development of two line rice hybrids. Since all the lines were completely sterile for more than 40 consecutive days during sterile phase, hybrid seed production utilizing these lines can be taken up in Coimbatore.

\section{Acknowledgement}

We are extremely thanks to Department of Rice, Centre for Plant Breeding \& Genetics, Tamil Nadu Agricultural University, Coimbatore for valuable suggestions and financial assistance provided during the course of investigation.

\section{References}

Borkakati, R.P., and Virmani, S.S. 1997. Determination of critical stage of fertility alteration in two thermosensitive genic male sterile mutants of rice. In: Proc. Int. Symp. On Two Line System of Heterosis Breeding in Crops. China National Hybrid Rice Research and Development Center, Changsha, China, 188-192.

Latha, R., and Thiyagarajan, K. 2010. Fertility alteration behaviour of Thermosensitive Genic Male Sterile lines in Rice Oryza sativa L. Elec. J. Plant Breeding, 1(4): 1118-1125.

Lu, X.G., Virmani, S.S., and Rencui, Y. 1998. In: Virmani, S.S., Siddiq, E.A. and Muralidharan, K. eds. Adv. Hybrid Rice Technol., International Rice Research Institute, 89-98.

Mou, T.M., Li, C.H., Young, Y.C., and Lu, X.G. 1998. Breeding and characterizing indica PGMS and TGMS lines in China.
In: Advances In Hybrid Rice Technology. Proceedings of the 3rd International Symposium on Hybrid Rice, 14-16 November, Hyderabad, India, Virmani, S.S., Siddiq, E.A. and Muralidharan, K. ed. International Rice Research Institute, Los Banos, Phillipines. 79-88.

Sanchez, D.L., and Virmani, S.S. 2005. Identification of thermosensitive genic male sterile lines with low critical sterility point for hybrid rice breeding. Philippine J. Crop Sci., 30(1): 19-28.

Viraktamath, B.C., and Virmani, S.S. 2001. Expression of thermosensitive genic male sterility in rice under varying temperature situations. Euphytica, 122: 137-143.

Virmani, S.S., and Sharma, H.L. 1993. Manual for Hybrid Rice Seed Production. International Rice Research Institute, Los Banos, Philippines. 57.

Virmani, S.S., Viraktamath, B.C., Casal, C.L., Toledo, R.S., Lopez, M.T., and Manalo, J.O. 1997. Hybrid Rice Breeding Manual, International Rice Research Institute, Los Banos, Philippines. 151.

Virmani, S.S. 1996. Hybrid rice. Adv. Agron., 57: 377-462.

Wu, X.J. 1997. Genetic strategies to minimize the risk in exploiting heterosis in rice by means of thermosensitive genic male sterility system. In: Proc. Int. Symp. On Two Line System of Heterosis Breeding in Crops. China National Hybrid Rice Research and Development Center, Changsha, China. 121-131.

Yuan, L.P. 1998. Hybrid rice breeding in China. In: Virmani, S.S., Siddiq, E.A. and Muralidharan, K. eds. Advances in hybrid rice technology. International Rice Research Institute, 27-33.

\section{How to cite this article:}

Sai Rekha, K., M. Kumar, R. Saraswathi, S. Mannonmani and Raveendran, M. 2017. Study on Critical Stages and Critical Sterility Point of Thermo-Sensitive Genic Male Sterile Lines of Rice for Two Line Hybrid Production. Int.J.Curr.Microbiol.App.Sci. 6(5): 2128-2135. doi: https://doi.org/10.20546/ijcmas.2017.605.238 